On the Polarisation of Light in the Rainbow

As I do not remember seeing any notice, in books on light and colour, about the polarisation of light in the rainbow, I think it my duty to relate the following facts, although I can scarcely think the appcarance has been unobserved till now.

Three times $I$ have tested the rainbow-light this summer, and each time I found it wholly polarised. On the first occasion, while looking at the rainbow, I thought I would examine it with a lourmaline, which $I$ lept in my pocket. I looked at the bow, through the tourmaline, and saw the bow; but on rotating the tourmaline the bow alternately disappeared and reappeated at every quarter turn : while the light from a stack of chimneys which stood within the bow remained apparently unchanged. From this I inferred that the light of the rainbow was wholly polarised, while the other light in its neighbourhood was not so.

I have observed the vanishing and reappearing of the light of the rainbow on rotating the tourmaline on two occasions since that. I have waited for these additional occasions to make sure of the fact, as I was called away from the first ob. servation; and when I could go back the rainbow had ranished.

The date of the second and third times are August 28 and September 4, 1873 .

Leicester, Sept. 5

Geo. Finlay

[The polarisation of the light of the rainhow was observed by Biot in 1811 , and by Brewster in 1812 . (See "Brewster's Optics," art. IS5.) With respect to rainbows by reflection, there are two kinds-(I) that observed by X. Z. Y., in which the light comes to the eye from the water. This is not thought worthy of special mention by Brewster. (2) That in which the light of the sun reflected from water strikes the shower and forms a bow not concentric with the common bow. (See "Brewster's Optics," art. I86.) It is very easy to see that these two kinds of bow form parts of the same cone whose axis is at the same altitude as the sun, but in the opposite azimuth.-J. C. M.]

\section{Autumnal Typhoid Epidemics}

THERE appear to be two types of these,-first, the malignant and dangerous, which breaks out in isolated spots and is usually traceable cither directly or indirectly to some sins of sewerage and a second or milder form, which extends over far larger areas, is much more general, and apparently unconnected with sewage exhalations or liquid contaminations. Some observations I have lately made suggest an explanation of the origin of this latter form. We have had just a moist and rather warm summer, followed by an unusually wet autumn. Turnips, swedes, bects, mangolds, cabbages, potatoes, peas, \&c., put forth luxurious foliage, and much of this, especially the lower leaves of turnips, swedes, and cabbages, have been rotted by the recent rains-so much so, that many a country lane that should have exhaled sweet balmy odours has beenj the abode of most unromantic stink. This is especially the case in the flat market garden areas that lie by the side of the Thames, and in these the most especially where cabbages are cultivated. I have no doubt that the partridge shooters of 1873 , who have largely availed them. selves of the cover of turnip-fields, will confirm my observation of their offensive odour.

Modern agriculture is, in England, chiefly developing and extending in the direction of root crops for caltle feeding, and the foliage of these is very liable to offensire decomposition under the conditions above named. When the autumn is hot and dry, their outer leavez, and also those of kitchen vegetables, drop off and return to the soil in a dry, crisp, and inodorous condition.

That the moist decomposition of such vegetable matter should supply nourishment to disease germs analogous to those which are fed by sewage, and that the exhalations of the decomposing vegetables should spread them after the manner of sewage exhalations, is obviously probable.

If I am right, the widely extended and milder forms of autumn epidemics should be most prevalent in such years as the present, and should prevail more especially in market-garden and cattle. feeding districts.

So far as my own means of obscriation extend, this appears to be the case, but as these are too limited to justify any positive conclusion, I throw out the above as a merely suggestive explanation, demanding further confirmation, which some of the renders of NATURE may be able to supply.

Woodside, Sept. 8
W. Matrieu WiLliajs

\section{Venomous Caterpillars}

OBSERVING a letter in NATURE respecting venomous caterpillars, I venture to offer a few remarks from personal experience.

The rough hairy caterpillars have a bad reputation everywherc. As a boy, the nurses told me if one got tight round my finger, it (and of course I understood the finger) would have to be cut off In Switzerland they are regarded by the common people as poisonous, though, as far as I know, without foundation.

In Portugal there is a most remarkable gregarious species, known as the "procession caterpillar," from the great numbers that may be seen advancing in a body. This kind has undoubtedly the power of causing very considerable irritation to a tender skin. A specimen once crawled up the arm of my little girl, then one year old, leaving the skin-surface red and in. flamed along its track; and there was a tradition at Lisbon of a child that had fallen into a mass of these larvx, and subse. quently died from the consequent inflammation.

In Brazil there is a species in the neighbourhood of Rio that, with regard to the formidable nature of its external clothing, is a veritable porcupine. It corresponds remarkably with the de. scription of the Burmese specimen, both in size and colour. The hairs, in a state of repose, are, however, but slightly erect, and it is only when irritated or alarmed that it raises them in hostile guise. There can be no question as to the stinging properties of these hairs, to which my wife, among others, can bear testimony; but as our experimental ardour did not induce us to grasp the creature, the consequences were never serious. The largest hairs must be nearly an inch long, and the points of all have a lighter appearance, as though singed. It was interesting to watch their elevation by the animal on the approach of the finger, as though by some electric attraction. The stinging sensation is analogous to that caused by a nettle. I am inclined to think that in this case the cause was likewise analogous. It is, however, possible that the hairs are brittle, or armed with articu. lated branches.

With reference to the power of detaching hairs possessed by some caterpillars, a remarkable instance came under my notice in Tiguea (Brazil). It was observed in the larva of a beautiful black and white butterfly with conspicuous yellow tail. The de. termining principle of its existence appeared to be rather economy than defence. Consequently the hairs with which its body was covered were utilised in the construction of its cocoon. For this purpose it was first clearly necessary to shed them; after which they were dexterously crossed and recrossed over the creature's body ensconced under the shadow of some convenient leaf. In this process, if thread was used at all, it was with the greatest economy.

As it was evident that such hairs must be well adapted to their purpose, I examined them under a good microscope, when I found them armed with short barbs on all sides, especially towards the extremities. The spines were tolerably thick, giving under the lens much the appearance of a sprig of juniper.

Berne, Switzerland

C. EDEX

IN reference to the article on venomous caterpillars in NATURE of the I4th inst., I beg to offer you, if the subject is not closed, my own very unpleasant experience.

On the Igth of June last, as I was sitting in my drawing. room near an open window, looking on the garden, I suddenly felt an itching sensation in my throat and arn, and on examining my dress I found a large brown long-haired caterpillar. In a few moments my skin, on the parts affected, was covered with a strong eruption attended with intense heat. Thinking it im. possible that the insect could have produced this inflammation, I sent for a doctor. After examining the slin he assured me he could see no other cause, and that the eruption resulted from the hairs of the caterpillar remaining in the skin.

He ordered me some simple applications, telling me that a few hours would bring relief. In this he was totally mistaken. The inflammation increased to the extent of producing general fever; I passed a sleepless night, and the next day it continued unabated. After that it very gradually subsided, but the traces of the eruption were visible ten days afterwards.

The insect could not, I imagine, have bitten me, as I felt nothing at the moment.

I have frequently been bitten by tropical insects, but. in no one instance have I suffered so severely, or becn so disfigured. The sensation reminded me somewhat of the prickly heat, only it was infinitely more intolerable.

There was no predisposing cause, as I was at the time in good 